\title{
Analysis of the Accuracy and the Surface Roughness of FDM/FFF Technology and Optimisation of Process Parameters
}

\author{
Radomir MENDRICKY, Daniel FRIS
}

\begin{abstract}
The work deals with the influence of process parameters on the quality and accuracy of parts produced by FDM (Fused Deposition Modelling)/FFF (Fused filament fabrication) technologies. The experiments were carried out on the 3D Ultimaker printer, PLA (Polylactid Acid) thermoplastics were used as the test materials. The practical part is divided into 3 experiments. First, the optimum temperature was set. In the next part, the parameters of retraction rate, retraction length and crossing speed were determined. In the last part, the impact of 13 parameters on the printing time, material consumption, surface quality and accuracy were determined. In this part of the experiment, the effect of the factors on the quality indicators was determined using the DoE Taguchi methodology. Subsequently, the influential parameters were determined by Paret's rule. The results showed how layer height and print speed are the most important factor for the print time. The parameters-percent filling, number of walls, and the height of the layer were marked as essential parameters affecting the material's consumption. The surface roughness and dimensional accuracy are most influenced by the height of the layer.
\end{abstract}

Keywords: 3D print; accuracy; additive manufacturing; experiment planning; process parameter; quality; surface roughness

\section{INTRODUCTION}

Customer pressure on personalised products forces businesses to change production processes. The effort of these new systems is production flexibility while maintaining low inventory and short lead times. This can be done with $3 \mathrm{D}$ printing. $3 \mathrm{D}$ print technology helps to accelerate the process of launching a new product. This technology is, therefore, an important tool for increasing the competitiveness of the company. At present, 3D printing is used to test the thoughts and ideas of engineers and designers. A major issue for 3D printing technology is productivity. It is generally known that $3 \mathrm{D}$ print productivity is lower compared to conventional machines (machining on CNC machines, injection moulding etc.) [1, 2]. The use of $3 \mathrm{D}$ printers as machines producing the final product in larger series is currently small, but the number of printers used in the future will grow.

In the research of work on a similar topic, many authors dealt, in particular, with the research of the influence of the layer height or the orientation of the printed part on the surface quality.

One of the studies in which these process variables were studied is the work [3]. In this study, the greatest influence on the surface quality was the orientation of the printed part, followed by another parameter, namely the layer height.

In [4], it was found that by selecting the right process parameters, the quality of the manufactured part would be improved. The parameters, such as layer height, fill shape, print speed, wall temperature and thickness were also tested in this work. At the end of the thesis, the author describes one of the parameters as critical, thus having a very large influence on the quality of the printed part. This parameter is the layer height. Another important parameter having a great impact on the good surface quality of the part is the thickness of the wall. Fill shape, print speed, and temperature parameters do not have a significant effect on the quality of the part.

The work [5] deals with the influence of process parameters on the quality and accuracy of the dimensions of the parts produced by the FDM technology. The results of this work are summarised in several recommendations that will improve the two outcomes examined.

- Using a smaller layer height will improve surface quality and dimensional accuracy.

- Larger extruded line widths improve surface quality, while the middle level of the extruded line size will improve dimensional accuracy.

- If the settings are set to overlap the extruded line, even by only $0.001 \mathrm{~mm}$, the surface quality deteriorates, as is the case with dimensional accuracy.

Vasudevarao's research [6] was focused on influence of layer height and part orientation on surface quality. They found out significant influence of surface quality, when the part is printed with $0.178 \mathrm{~mm}$ layer thickness and orientation 70 (degrees).

The paper [7] is focused on finding significant factors responsible for surface roughness. The results revealed that the layer height has higher effect on roughness than the other factors like print speed or road width.

The paper [8] is focused on the analysis and evaluation of effects of surface angle, layer thickness, cross-sectional shape of the filament, and overlap interval on surface roughness. It was found that the shape of filament cross section is important for lower roughness and that the layer thickness also affects the surface quality. The road width overlap has a significant effect on surface quality. There was made a calculation of roughness prediction. It was demonstrated that an elaborate prediction of the surface roughness of FDM parts can be performed with the presented surface roughness expression.

Mahmood et al. [9] present in their research an experimental approach to investigate the effects of variation in the process parameter settings on the geometrical properties of the printed parts. A test sample was designed to include simple geometric features which allows for measurement of both dimensional accuracy and geometric characteristics. Taguchi's design of experiment statistical approach was used to establish the relationship between varying process parameter settings on the geometrical properties of the test sample. His results have shown that, for dimensional accuracy, the deviation from nominal values increases with increasing feature sizes for 
all geometric features and the deviation from nominal dimensions is larger for recessed features as compared to extruded features.

In paper [10] the holes and cylinders of the cylindrical elements are investigated in terms of achievable geometrical accuracy. For this purpose, different test specimens that allow measurement of inner and outer diameters from 3 to $80 \mathrm{~mm}$ were designed. All specimens were measured with a coordinate measuring machine to evaluate deviations from the nominal dimension and form deviations. Thus, it was possible to visualize how deviations on cylindrical elements manufactured in FDM occur. In order to counteract these deviations and to improve the dimensional accuracy, different shrink factors and filling patterns were investigated. Research has shown that the measured value increases with increasing nominal diameter. However, whether there is an undersize or oversize depends on the respective nominal diameter. The roundness of cylindrical elements manufactured in the XYplane is very constant and lower than for elements manufactured in the Z-alignment.

This paper [11] answers the question on "what build orientation should be used to minimise the adverse effects of surface roughness? " There is described a methodology and software implementation that provides the designer with a computer graphics based visualisation of RP model surface roughness. The surface roughness values were obtained through an extensive empirical investigation of several RP techniques. These are used as the database for a visualisation algorithm that represents varying surface roughness of the RP model as colour shading within a CAD image. The author et al investigated surface roughness for different materials. They found that for ABS material the surface roughness values for FDM processes ranged between $9 \mu \mathrm{m}$ and $40 \mu \mathrm{m}$, when using layer thickness of $0.25 \mathrm{~mm}$

The analysis of the optimal process parameters for obtaining good surface finish and dimensional accuracy was done by Akande et al. [12]. The authors employed a layer height of 0.25 and $0.5 \mathrm{~mm}$, varying the filling density and speed of deposition. They found that the surface roughness for PLA material ranged between $2.46 \mu \mathrm{m}$ and $22.48 \mu \mathrm{m}$. In another research [13], there was used layer thickness between $0.1 \mathrm{~mm}$ and $0.4 \mathrm{~mm}$ to create PLA samples using a FDM process. The measured surface roughness fluctuated around $10 \mu \mathrm{m}$.

In each of these outcomes, it was concluded that process parameters have a significant effect on the surface quality and dimensional accuracy. It is also evident from the searches that most of the authors are mostly focused on one-sided experiments. For example, the influence of process parameters on surface roughness [4, 11, 13], on dimensional or geometrical accuracy [14-17] is investigated, or mechanical properties and topography of printed samples are investigated [18-21].

Our research is focused on procedures and methodologies for performing complex research on the process parameters of printing using FDM technology, from design optimal temperature, determination of retraction parameters to using DoE Taguchi methodology to define influential parameters for print time, material consumption as well as surface roughness and dimensional accuracy of samples. Modern 3D optical contactless scanning methods are used for this.

\section{METHODS AND MATERIALS}

In the case of the FDM technology used for testing purposes, the resulting product is produced by melting the thermoplastic in the form of a string. This is then delivered through the nozzle to the building platform. After the entire layer is made, the platform is moved downward by the layer height. Repeating this action will produce the desired product [22]. The whole experiment was performed on the $3 \mathrm{D}$ Ultimaker $2+$ printer. This printer does not have a heated chamber. It allows to heat the platform up to $100^{\circ} \mathrm{C}$ (suitable for ABS material, $60{ }^{\circ} \mathrm{C}$ for PLA is recommended) and the working temperature of the nozzle can be up to $260^{\circ} \mathrm{C}$. PLA thermoplastic was selected as the test material. In its processing, the release of dangerous particles to the health does not occur to such an extent as is the case with the processing of ABS (Akrylonitril Butadien Styren) thermoplastic [23, 24]. The printer processing these thermoplastics may be located in a closed space. As a representative material for this research, the $3 D$ PROI material from Innofil manufacturer was chosen. The data for the 3D printing (STL files) was generated in the software CURA v. 2.5.

Due to the large number of process parameters (up to 200 in the software), it was necessary to design a methodology of the experiments to test the number of parameters. Since it would be difficult to process all the parameters, those were chosen which, in our opinion, have a significant impact on the quality indicators. There were 17 of the parameters in total and they are shown in Tab. 1.

Table 1 The selected process parameters

\begin{tabular}{|c|}
\hline Nozzle temperature \\
\hline Retrieval length \\
\hline Retrieval speed \\
\hline Layer height \\
\hline Width of the extruded line \\
\hline Number of walls \\
\hline Thickness of the top layer \\
\hline Fill shape \\
\hline Fill print speed \\
\hline Wall print speed \\
\hline Print speed of top layers \\
\hline Crossing speed \\
\hline Support shape \\
\hline Quantity of extruded material \\
\hline Orientation of the part on the base \\
\hline Percentage of fill \\
\hline The shape of the top layer filler \\
\hline
\end{tabular}

Due to the number of parameters, it was necessary to set up a methodology of the experiments that will determine which parameters most influence the quality indicators. If 3 levels are set for each parameter, there would be a large number of combinations from the perspective of a fully factorial experiment. Therefore, the DoE method by Taguchi [25] was chosen. He also used it in his research, for example, $[9,26,27]$. This method is based on the orthogonal field principle. These fields are prescribed for a number of factors and levels. The orthogonal field determines a way of combining the levels of factors [28, 29]. Since there are no orthogonal fields for 17 factors, the experiment is divided into 3 parts. 


\subsection{Determination of Optimum Temperature}

The first part of the experiment deals with the optimum temperature of the nozzle for the material. For the purpose of this experiment, a test sample was designed (see Fig. 1). The sample is divided into 6 segments, each of which is assigned a different temperature. The temperature was set in the range of $230{ }^{\circ} \mathrm{C}$ to $180{ }^{\circ} \mathrm{C}$. The test samples for the defined velocities of $v_{1}=30 \mathrm{~mm} / \mathrm{s}, v_{2}=65 \mathrm{~mm} / \mathrm{s}$ and $v_{3}=$ $100 \mathrm{~mm} / \mathrm{s}$ have been printed. The problem of nozzle temperature determination has two pitfalls. The first option is that the nozzle does not melt the material due to a too low nozzle temperature. This possibility is reflected in the workpiece by spaces in the layers, the so-called under extrusion phenomenon. On the other hand, in the case of too high a temperature, bubbles are formed, which can then be observed on the surface of the printed part. The optimum temperature was determined subjectively. The optimal temperature is chosen as the temperature at which the under extrusion phenomenon no longer occurs.
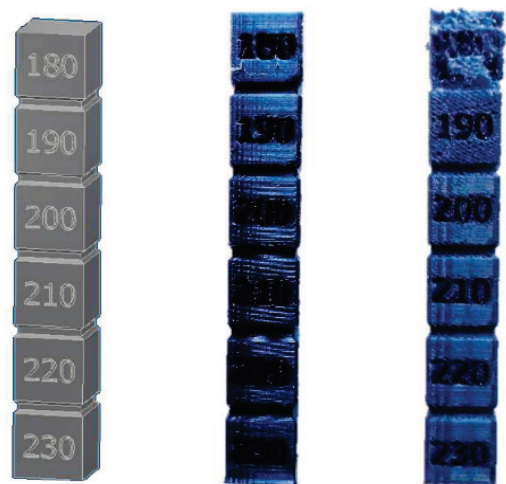

Figure 1 The designed sample for experiment $1 /$ sample printed at $30 \mathrm{~mm} \cdot \mathrm{s}$ $1 /$ sample printed at $100 \mathrm{~mm} \cdot \mathrm{s}^{-1}$

\subsection{Determination of the Retractions}

In this step, it was tried to eliminate or reduce the "stringing" problem. This phenomenon occurs during the print head passes. Due to excess pressure in the nozzle, the material is extruded through the nozzle. This material is then attached to the part to which the print head passes. The effect of inappropriately adjusted rectangles is shown in Fig. 2.

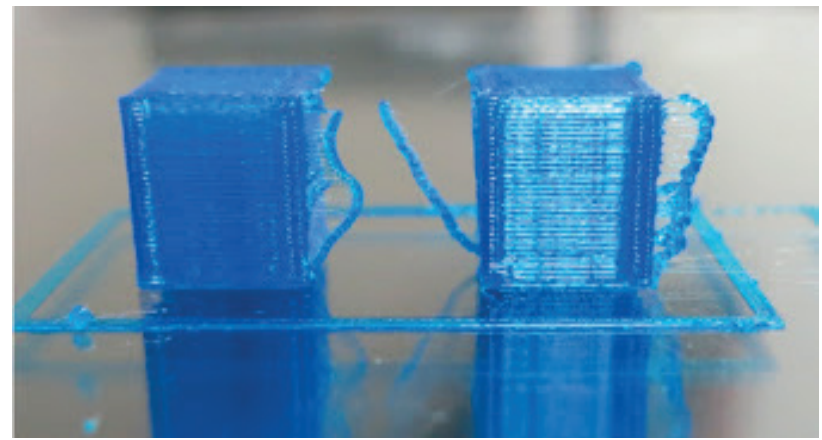

Figure 2 The "stringing" problem

There have been selected 4 parameters that have an impact on our issue from our point of view. These are the length and retraction rate parameters, the crossing speed and the nozzle temperature. The experiments were determined according to DoE Taguchi. For the 4 factors, a 3 level experiment was chosen. For this setting, the orthogonal field L9 is specified. Therefore, a total of 9 experiments should be carried out for each material. In order to carry out the experiment, it was necessary to set the levels of the factors. The specified levels can be found in Tab. 2.

Table 2 The selected factor levels for experiment 2

\begin{tabular}{|l|c|c|c|c|}
\hline \multicolumn{1}{|c|}{ Factor } & Level 1 & Level 2 & Level 3 & Unit \\
\hline Retraction speed & 10 & 20 & 40 & $\mathrm{~mm} / \mathrm{s}$ \\
\hline Length of retraction & 5 & 7 & 12 & $\mathrm{~mm}$ \\
\hline Nozzle temperature & 185 & 200 & 220 & ${ }^{\circ} \mathrm{C}$ \\
\hline Speed of crossings & 50 & 150 & 250 & $\mathrm{~mm} / \mathrm{s}$ \\
\hline
\end{tabular}

The test sample, which was designed for the purposes of these experiments, is shown in Fig. 3.

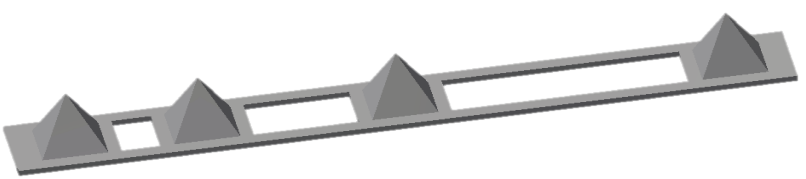

Figure 3 The test sample for experiment 2

The samples were evaluated qualitatively. Those that had the shortest strings or none were rated 1 . The samples that were strung across the length were rated 5 . The samples that could not be included in one group were rated 3 . They are followed by the calculation of the average result levels for the selected parameters. From these values, the factor's effect can then be calculated.

\subsection{Influence of the Process Parameters on Quality and Dimensional Accuracy}

If the values of the parameters that were set in the previous experiments are assumed to be constant, only 13 parameters remain. L27 exists for this number of orthogonal field parameters [30]. This field is set for 3 levels of factors. It was necessary to set the parameter levels. These levels are shown in Tab. 3.

Now it was necessary to define a test sample for this experiment. The sample contains both convex and concave surfaces, flat surfaces, chamfers, base primitives, and relief. While several different additive manufacturing (AM) test parts were developed in the past, there are no current standard test parts [31]. The effort was to determine the dimensional accuracy of both small objects in the order of millimetres and large objects in the order of tens of millimetres. Because the goal is to determine the printability of small parts at different process parameter settings, it is necessary to place different sizes of primitives on the sample. Surface roughness was investigated in red marked areas. Dimensional accuracy was determined by the Atos II 400 3D scanning system. This system allows the lens to change the size of the measurement volume by changing the lens. This indicates the size of the scene captured by one scan of the scanner. Therefore, the sample should be designed to fit into the scanning volume. The size of the measuring volume was $55 \times 44 \times 30 \mathrm{~mm}$. This lens will also provide for the digitisation of very small objects on the sample being tested. The proposed test sample is shown in Fig. 4. 


Table 3 The selected factor levels for experiment 3
\begin{tabular}{|l|c|c|c|c|}
\hline Factor & Level 1 & Level 2 & Level 3 & Unit \\
\hline Layer height & 0.06 & 0.12 & 0.18 & $\mathrm{~mm}$ \\
\hline Extruded line width & 0.2 & 0.22 & 0.25 & $\mathrm{~mm}$ \\
\hline Number of walls & 3 & 4 & 6 & - \\
\hline Top layer thickness & 0.66 & 0.72 & 0.78 & $\mathrm{~mm}$ \\
\hline Top layer shape & Lines & Concentric & Zig Zag & - \\
\hline Percentage of fill & 20 & 30 & 40 & $\%$ \\
\hline Fill shape & Triangles & Grid & $\begin{array}{c}\text { Concentric } \\
3 \mathrm{D}\end{array}$ & - \\
\hline Fill print speed & 30 & 65 & 100 & $\mathrm{~mm} / \mathrm{s}$ \\
\hline Wall print speed & 20 & 30 & 40 & $\mathrm{~mm} / \mathrm{s}$ \\
\hline $\begin{array}{l}\text { Top layer print } \\
\text { speed }\end{array}$ & 20 & 35 & 50 & $\mathrm{~mm} / \mathrm{s}$ \\
\hline $\begin{array}{l}\text { Support shape } \\
\text { Concentric } \\
3 \mathrm{D}\end{array}$ & Zig Zag & Lines & - \\
\hline $\begin{array}{l}\text { Orientation of the } \\
\text { part on the base }\end{array}$ & 0 & 23 & 45 & $\circ$ \\
\hline $\begin{array}{l}\text { \% of extruded } \\
\text { material }\end{array}$ & 99 & 100 & 101 & $\%$ \\
\hline
\end{tabular}

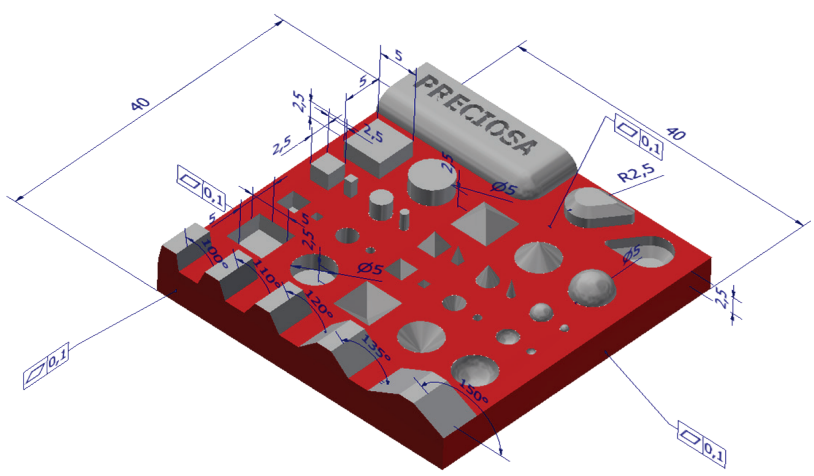

Figure 4 The test sample for experiment 3

Surface quality was determined using an SV2000 touch probe. This device was fitted with a touch tip with the following parameters: Peak radius $R=0.005 \mathrm{~mm}$ and angle $\alpha=90^{\circ}$. The top layer and the side wall of the test sample were found to be interesting surfaces for evaluation. On each test sample, a total of 5 measurements were made for both measured surfaces. Using the Surfpak software, the measurement of the measured profile and its magnification was recorded. Subsequently, the surface roughness parameters were calculated. For the measurement of the top layer, the test specimen was laid on the positioning table, see Fig. 5. When measuring the side of the test specimen, it was necessary to clamp the specimen into the clamp.

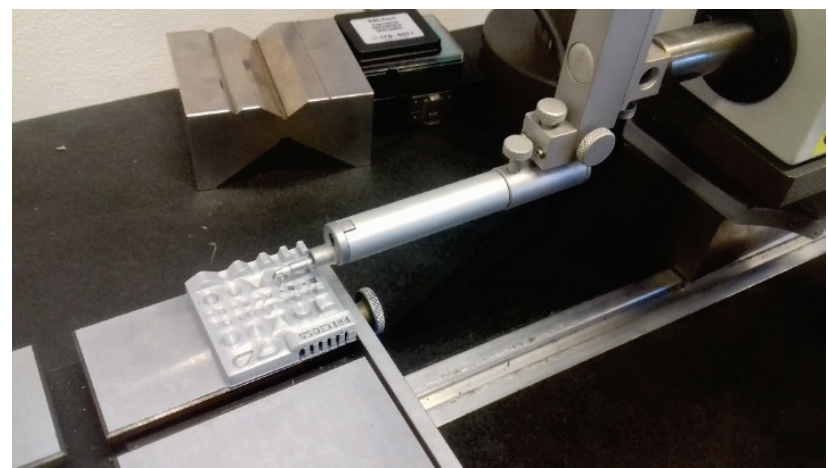

Figure 5 Measurement of the surface roughness of the top layer

Fig. 6 shows the roughness profile of the surface recorded by the profile gauge. This profile was measured on the side of the sample. The profile shows the individual layers of the printed part.
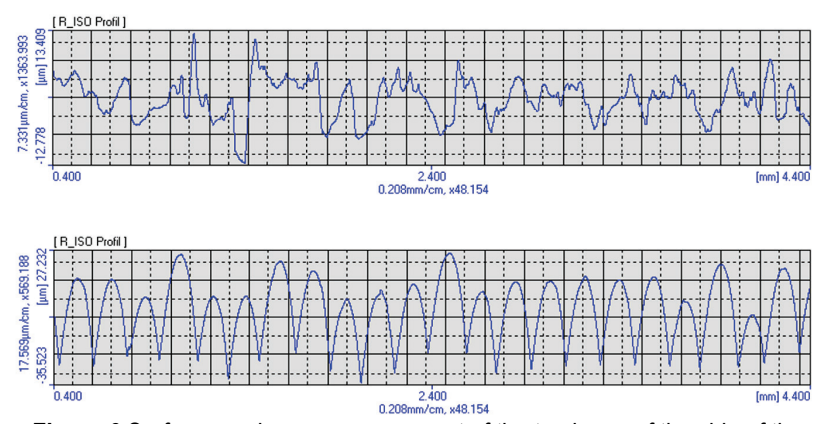

Figure 6 Surface roughness measurement of the top layer, of the side of the sample

The test sample was scanned by the Atos II 400 from GOM company. Since this is an optical method of digitisation, it is recommended to adjust the surface of the scanned part. Altogether the surface treatment was tested in 3 ways. The first digitisation method was carried out without an antireflection layer. For further scanning, it was used chalk spray with a Helling 3D Scan spray and a Titanium powder $\left(\mathrm{TiO}_{2}\right)$ spray dissolved in ethanol using a spray gun. By comparing the quality of the scanned data, it was found that the test sample without the anti-reflection layer was not fully digitised. When using both chalk and titanium spraying, the complete digitisation of the component was made, see Fig. 7. The difference in the size of the variations was not nearly obvious, so it was decided to apply the chalk coating to the other samples, which is easier to apply. The results of these experiments corresponded to the research published in professional publications (e.g., $[32,33]$ ). In addition, it has been shown that the properly applied anti-reflection layer does not to a high degree affect the precision of 3D scanning because the thickness of the applied layer is in the order of micrometres (approximately to $5 \mu \mathrm{m}$ for $\mathrm{TiO}_{2}$ and to $10 \mu \mathrm{m}$ for Helling 3D Scan spray).
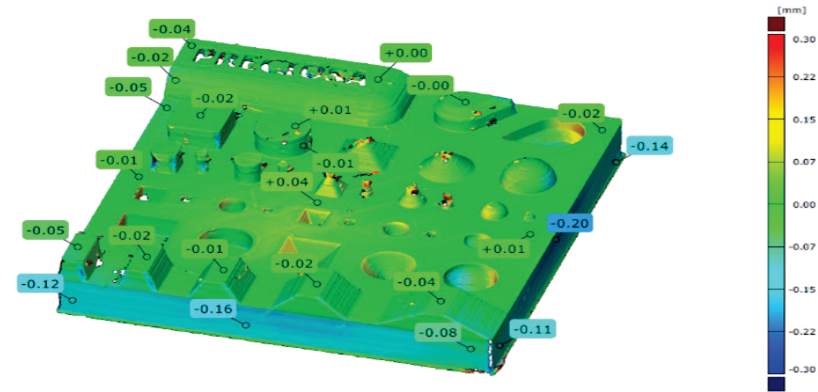

Figure 7 Colour map of the deviations

All detected deviations were detected using the software GOM Inspect V8 Professional. Because the test sample includes objects with different geometric and dimensional characteristics, it was necessary to define how to compare the size of the deviations of each object. It was decided to divide the examined objects into a sample of four groups. That is, it would be possible to compare the diameters of the cylinders with the diameters of the spheres, because when cutting into individual layers, there is always a circular motion. The same applies to the dimensions of the individual objects. Only the same or similarly sized large objects can be compared. The evaluated groups are listed in Tab. 4. An example of the 
group "Dimensions $Y$ (heights of cylinders and blocks)" is shown in Fig. 8.

Table 4 The evaluated groups
\begin{tabular}{|l|c|}
\hline \multicolumn{1}{|c|}{ Evaluated group } & $\begin{array}{c}\text { Measure in } \\
\text { the plane }\end{array}$ \\
\hline Cylinder diameters $(\phi 2.5 ; 5 \mathrm{~mm})$ & $X Z$ \\
\hline Dimensions $X Z($ sample $40 \mathrm{~mm})$ & $X Z$ \\
\hline Dimensions $X Z$ (block $2.5 ; 5 \mathrm{~mm})$ & $X Z$ \\
\hline Dimensions $Y$ (heights of cylinders and blocks $2.5 \mathrm{~mm})$ & $Y$ \\
\hline
\end{tabular}

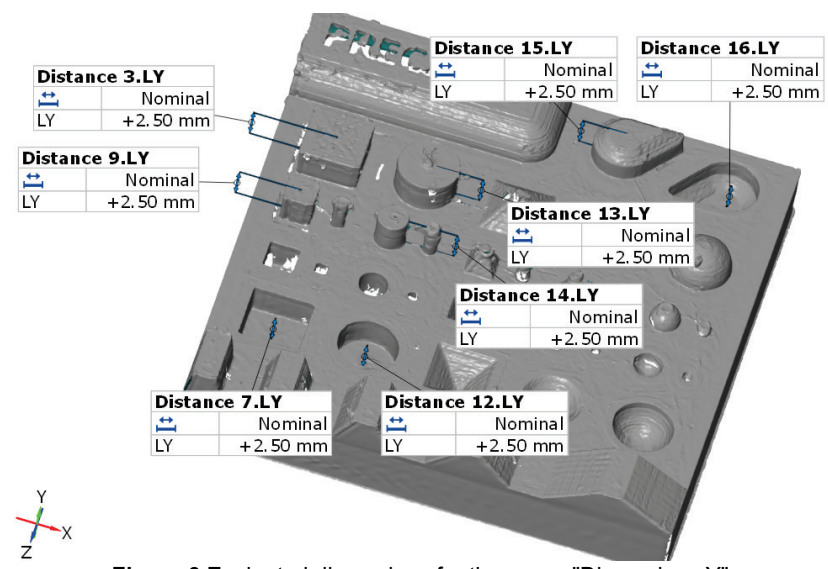

Figure 8 Evaluated dimensions for the group "Dimensions Y"

\section{RESULTS}

\subsection{Determination of the Optimum Temperature}

A total of 3 samples was printed, each for a specific speed $\left(v_{1}=30 \mathrm{~mm} / \mathrm{s}, v_{2}=65 \mathrm{~mm} / \mathrm{s}, v_{3}=100 \mathrm{~mm} / \mathrm{s}\right)$. By evaluating the surface of the individual segments of the test sample, the temperature was determined at which the under extrusion phenomenon no longer occurs. The selected temperatures (see Tab. 5) ensure the proper melting of the material in the nozzle and continuous flow. The selected temperatures do not take the connection of the layers themselves into account, and at low temperatures there is no complete bonding of the layers, this affects the mechanical properties.

Table 5 The set temperatures

\begin{tabular}{|l|c|c|}
\hline & Printing speed $/ \mathrm{mm} / \mathrm{s}$ & Temperature $/{ }^{\circ} \mathrm{C}$ \\
\hline Level 1 & 30 & 185 \\
\hline Level 2 & 65 & 190 \\
\hline Level 3 & 100 & 210 \\
\hline
\end{tabular}

\subsection{Determination of the Retractions}

Proper retraction settings ensure a sufficient amount of material in the nozzle. It has been found that the retraction setting itself affects the nozzle clogging or filament grinding. With too aggressive settings, meaning high retraction rates and short retraction lengths, the filament was ground by the feed roller. The methodology chosen by us has provided us with the setting of suitable parameters that have led to the elimination of the stringing problem. The printed samples were evaluated qualitatively. The results of the partial experiments can be seen in Tab. 6 . From this data it is possible to create a graph. Because the strings on the printed object are an effort to minimise, the goal is to achieve a result that approximates the value of 1 .
Table 6 The results of experiment no. 2

\begin{tabular}{|c|c|c|c|c|c|}
\hline 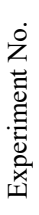 & 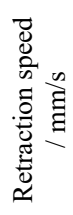 & 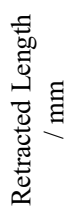 & 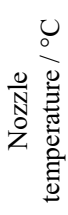 & 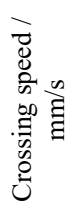 & 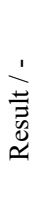 \\
\hline 1 & 10 & 3 & 185 & 50 & 5 \\
\hline 2 & 10 & 7 & 200 & 150 & 3 \\
\hline 3 & 10 & 12 & 220 & 250 & 3 \\
\hline 4 & 20 & 3 & 200 & 250 & 1 \\
\hline 5 & 20 & 7 & 220 & 50 & 5 \\
\hline 6 & 20 & 12 & 185 & 150 & 1 \\
\hline 7 & 40 & 3 & 220 & 150 & 5 \\
\hline 8 & 40 & 7 & 185 & 250 & 3 \\
\hline 9 & 40 & 12 & 200 & 50 & 3 \\
\hline
\end{tabular}

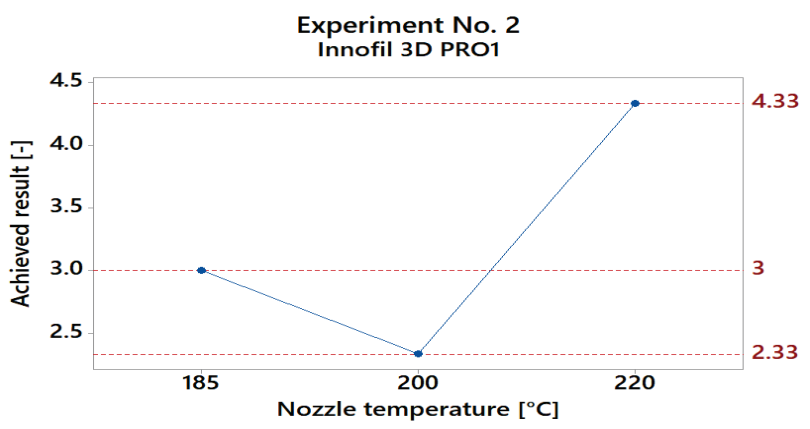

Figure 9.The influence of the nozzle temperature on the stringing problem

Fig. 9 shows that the nozzle temperature parameter should be set to $200{ }^{\circ} \mathrm{C}$.

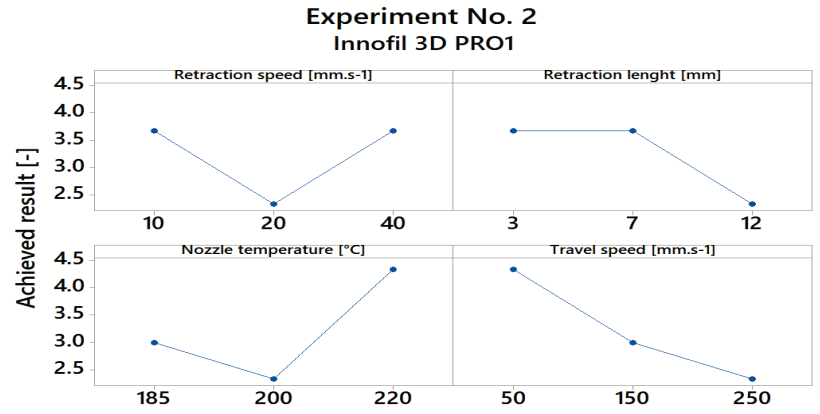

Figure 10 The influence of the process parameters on the stringing problem

In the same way, the other variables were evaluated. Fig. 10 shows the values of the parameters that will remove the strings.

Because the nozzle temperature in experiments no. 1 and 2 was tested, it is necessary to determine which value to choose for the optimal setting. It was proceeded as follows: Experiment no. 2 was performed under the specified conditions-printing speed $v=30 \mathrm{~mm} / \mathrm{s}$. The value of the parameter that led to the removal of the strings on the printed object $\left(200{ }^{\circ} \mathrm{C}\right)$ was compared to the temperature of experiment no. 1 for the used print speed, i.e., $v=30 \mathrm{~mm} / \mathrm{s}$. When temperatures above $185^{\circ} \mathrm{C}$ are used, the material in the nozzle melts correctly, so the temperature found in experiment no. $2\left(200{ }^{\circ} \mathrm{C}\right)$ was chosen as the temperature at which work continued.

From Fig. 9 the following can be deduced:

a) At higher retraction rates, there is no faster way of pulling of the filament from the extruder melt zone. Conversely, the feed roller is cut into the filament, causing slippage. 
b) The method of transporting the filament is carried out on the tested printer by means of a cable. It is obvious that longer retraction lengths are more suitable for this mode of transport.

c) The material at lower temperatures $\left(185^{\circ} \mathrm{C}\right)$ will be more viscous, this fact could reduce the extrusion of the material through the nozzle. However, the results of the experiment show that a higher temperature $\left(200^{\circ} \mathrm{C}\right)$ led to better results. This, however, was not true to a certain extent; more strings were formed when using a high temperature $\left(220^{\circ} \mathrm{C}\right)$ than at $185^{\circ} \mathrm{C}$.

d) For the crossing speed parameter values it was assumed that no strings would occur as the print head passes so fast that there is no leakage of the thermoplastic material from the nozzle. This assumption was confirmed by the experiment.

The selected parameter values: retraction rate $=20$ $\mathrm{mm} / \mathrm{s}$, retraction length $=12 \mathrm{~mm}$, nozzle temperature $=200$ ${ }^{\circ} \mathrm{C}$ and speed of transitions $=250{ }^{\circ} \mathrm{C}$. The detected values for experiments no. 1 and 2 will be used to process the final part of the experiment.

\subsection{The Influence of the Process Parameters on the Quality and Dimensional Accuracy}

In addition to the parameters that were worked on in the previous sections, the additional quantities that will be constant throughout the experiment have been determined. These are the parameters listed in Tab. 7.

Table 7 The constant values of the 3rd experiment

\begin{tabular}{|l|c|c|}
\hline Number of lower layers & 3 & Unit \\
\hline Temperature of the first layer & 215 & ${ }^{\circ} \mathrm{C}$ \\
\hline Heat pad temperature & 60 & ${ }^{\circ} \mathrm{C}$ \\
\hline Cooling fan & 100 & $\%$ \\
\hline Height of the first layer & 0.2 & $\mathrm{~mm}$ \\
\hline Print speed of the first layer & 15 & $\mathrm{~mm} / \mathrm{s}$ \\
\hline
\end{tabular}

A total of 13 parameters remain to be tested. For the 13 parameters tested on three levels, the orthogonal field L27 is prescribed according to the DoE Taguchi methodology. This field prescribes a total of 27 experiments and the setup of partial experiments. For further steps, the levels for each parameter should be set. The values of these levels were determined on the basis of previous experience. After generating all of the G-codes, it was found that the print timeout for this part of the experiment was 61 hours and 7 minutes. During this portion, a total of $153 \mathrm{~g}$ of material will be consumed.

\subsection{The Impact of the Process Parameters on the Print Time and Material Consumption}

Our goal is to ensure a compromise between the quality, accuracy and cost of the printed object. Therefore, as an additional step, it is necessary to analyse the impact of the process parameters on the print time and material consumption. The time of the partial experiment printing as well as the material consumption are known, so the factor values can now be determined. These values are determined by the statistical software Minitab. In order to determine which parameter has a major impact on the print time and material consumption, an absolute factor value has been determined for each parameter. Then these values were compared from the largest to the smallest, and influential parameters were determined using Paret's rule. Paret's rule states that " $80 \%$ of the consequences are caused by $20 \%$ of the causes". In our case, this sentence can be reformulated as " $20 \%$ of the parameters have a major impact on the quality indicators". The ordered parameters can be found in Tab. 8 .

Table 8 The impact of the process parameters on the print time

\begin{tabular}{|l|c|c|}
\hline \multicolumn{1}{|c|}{ Parameter } & $\begin{array}{c}\text { Part percentage } \\
/ \%\end{array}$ & $\begin{array}{c}\text { Cumulative } \\
\text { frequency } / \%\end{array}$ \\
\hline Layer height & 37.41 & 37.41 \\
\hline Wall print speed & 14.35 & 51.76 \\
\hline Top later print speed & 13.65 & 65.41 \\
\hline Print fill speed & 12.94 & 78.35 \\
\hline Number of walls & 4.24 & 82.59 \\
\hline Fill percent & 3.29 & 85.88 \\
\hline Top layer thickness & 3.06 & 88.94 \\
\hline Width of extruded line & 2.82 & 91.76 \\
\hline Shape of top layer & 2.35 & 94.12 \\
\hline Extruded materials possibilities & 2.12 & 96.24 \\
\hline Shape supported & 1.41 & 97.65 \\
\hline Orientation of the part at the base & 1.18 & 98.82 \\
\hline Fill shape & 1.18 & 100 \\
\hline
\end{tabular}

Data from the table can be represented in this way variations with layer height, wall print, top layer and fill speed will cause significant changes in the print time. In the same way, it is possible to determine to what extent the material consumption can be influenced by the process parameters. The parameters-percent filling, number of walls, and the height of the layer-were marked as essential parameters affecting the material's consumption.

It is now possible to look at the magnitude of the deviations and the surface quality of the $3 \mathrm{D}$ printed parts. First, attention was paid to surface roughness. The surface quality of the top layer was first measured. After the results were processed, it was possible to determine the influence of the individual parameters on the surface roughness of the top layer. The order of these parameters is shown in Tab. 9.

Table 9 The parameters that have a major influence on the surface roughness of the top layer

\begin{tabular}{|l|}
\hline \multicolumn{1}{|c|}{ Parameter } \\
\hline Layer height \\
\hline The shape of the top layer \\
\hline Fill print speed \\
\hline Speed of the top layer \\
\hline Filling shape \\
\hline Percentage of the fill \\
\hline Orientation of the part on the base \\
\hline
\end{tabular}

The sequence of the process parameters influencing the roughness of the wall surface was then determined. The sequence of the parameters is shown in Tab. 10.

Table 10 The parameters that have a major influence on the surface roughness of the side wall

Layer height

Parameter

Speed of wall printing

Orientation of the part on the base

It is now possible to say which parameters have a major influence on the quality of the surface roughness. During the experiment, it has been also determined which 
surface roughness values $R a$ can be achieved by $3 \mathrm{D}$ printing. The best and worst results are shown in Tab. 11 .

Table 11 The measured surface roughness $R a$ results Surface roughness values Top layer roughness $\mathrm{Ra} / \mathrm{\mu m}$ Side wall roughness $R a / \mu \mathrm{m}$

The next step was to determine the influence of the process parameters on the size of the dimensional deviations. After evaluating all the measurement protocols, the minimum, mean and maximum deviations of the objects were determined under investigation in each group. These results are shown in Tab. 12.

Table 12 Measured values of dimensional deviations
\begin{tabular}{|l|c|c|c|}
\hline \multicolumn{1}{|c|}{ Evaluated group } & $\begin{array}{c}\text { min } \\
/ \mathrm{mm}\end{array}$ & $\begin{array}{c}\text { mean } \\
/ \mathrm{mm}\end{array}$ & $\begin{array}{c}\mathrm{max} \\
/ \mathrm{mm}\end{array}$ \\
\hline Cylinder diameters $(\varnothing 2.5 ; 5 \mathrm{~mm})$ & 0.04 & 0.09 & 0.13 \\
\hline Dimensions $X Z(40 \mathrm{~mm})$ & 0.02 & 0.14 & 0.31 \\
\hline Dimensions $X Z(2.5 ; 5 \mathrm{~mm})$ & 0.04 & 0.07 & 0.13 \\
\hline Dimensions $Y$ (heights) & 0.02 & 0.04 & 0.08 \\
\hline
\end{tabular}

The process of determining the influence of the process parameters on the size of the variance proceeded in the same way as in the previous parts of the experiment. Each evaluated group contains a set of process parameters that have a major impact.

Table 13 The parameters that have a major effect on the size of the dimensional deviations

\begin{tabular}{|c|c|c|c|}
\hline $\begin{array}{c}\text { Cylinder } \\
\text { diameters }\end{array}$ & $\begin{array}{c}\text { Dimensions } X Z \\
(40 \mathrm{~mm})\end{array}$ & $\begin{array}{c}\text { Dimensions } X Z \\
(2.5 ; 5 \mathrm{~mm})\end{array}$ & $\begin{array}{c}\text { Dimensions } Y \\
\text { (heights })\end{array}$ \\
\hline Layer height & Fill print speed & Layer height & Layer height \\
\hline $\begin{array}{c}\text { Orientation of } \\
\text { the part on the } \\
\text { base }\end{array}$ & $\begin{array}{c}\text { Orientation of } \\
\text { the part on the } \\
\text { base }\end{array}$ & $\begin{array}{c}\text { Extruded } \\
\text { material }\end{array}$ & Fill shape \\
\hline $\begin{array}{c}\text { Number of } \\
\text { walls }\end{array}$ & $\begin{array}{c}\text { The width of } \\
\text { the extruded } \\
\text { line }\end{array}$ & Fill print speed & Fill print speed \\
\hline Fill percent & Fill shape & Wall print speed & $\begin{array}{c}\text { Top layer print } \\
\text { speed }\end{array}$ \\
\hline $\begin{array}{c}\text { Fill print speed } \\
\text { speed }\end{array}$ & $\begin{array}{c}\text { Wall print } \\
\text { thickness }\end{array}$ & & \\
\hline $\begin{array}{c}\text { Wall print } \\
\text { speed }\end{array}$ & $\begin{array}{c}\text { Shape } \\
\text { supported }\end{array}$ & & \\
\hline $\begin{array}{c}\text { Top layer print } \\
\text { speed }\end{array}$ & & & \\
\hline
\end{tabular}

The parameters in Tab. 13 are ranked according to the degree of impact on the evaluated group of the variations. These parameters, therefore, have a major effect on the size of the variations.

\section{CONCLUSIONS}

The experiment results can be viewed from several perspectives. The experimental methodology has been set for performing complex research on the process parameters of printing for FDM technology. The procedure for designing the optimal temperature and for determination of retraction parameters was introduced and DoE Taguchi methodology was used to define influential parameters for print time, material consumption as well as surface roughness and dimensional accuracy of samples. Modern 3D optical contactless scanning methods were used for this. The surface roughness values that can be achieved by $3 \mathrm{D}$ printing technologies have been determined. Likewise, which deviations can be made with a particular setting. This was not the main reason for this research.

The aim of the work was to ensure the efficient use of a $3 \mathrm{D}$ printer with respect to the costs and quality required by the contracting authority. It was assumed that with increasing printing time the quality of printed parts will grow. Using experiments, this claim was refuted. Parameters that most influenced the examined quality indicators were found experimentally. By comparing the results of the process parameter influence to the print time and the size of the cylinder diameter deviation, it was found that the magnitude of the deviation is significantly influenced by parameters that were not marked as parameters having a significant effect on the print time. This will help us improve the cylinder diameter deviation without substantially changing the print time. Thus, the surface roughness can also be influenced. A series of experiments has set the settings for achieving the best results. The most influential parameters on the surface roughness of the top layer were the layer height, the shape of the top layer and the fill print speed. The surface roughness of the side wall was most affected by the layer height, the speed of walls printing and the orientation of the part on the base. Another benefit of the experiments is a set of real samples. On these formulas, a non-expert in $3 \mathrm{D}$ printing can present which results can be achieved.

\section{Acknowledgements}

This paper was written at the Technical University of Liberec as part of the project (21278) "Optimization of manufacturing systems, 3D technologies and automation" with the support of the Specific University Research Grant, as provided by the Ministry of Education, Youth and Sports of the Czech Republic in the year 2019.

\section{REFERENCES}

[1] Achillas, C., Aidonis, D., Iakovou, E., Thymianidis, M., \& Tzetzis, D. (2015). A methodological framework for the inclusion of modern additive manufacturing into the production portfolio of a focused factory. Journal of Manufacturing Systems, 37, 328-339. https://doi.org/10.1016/j.jmsy.2014.07.014

[2] Thomas, D. S. \& Gilbert, S. W. (2014). Costs and Cost Effectiveness of Additive Manufacturing (No. NIST SP 1176; p. NIST SP 1176). https://doi.org/10.6028/NIST.SP.1176

[3] Tejendrasinh, S. R., Dave, D. K. G., Dharmesh, B. P., \& Viral, N. T. (2014). An Experimental Investigation of Effect of Process Parameters on Surface Roughness of Fused Deposition Modeling Built Parts. International Journal of Engineering Research \& Technlogz (IJERT), 3(4), 22702274.

[4] Pérez, M., Medina-Sánchez, G., García-Collado, A., Gupta, M., \& Carou, D. (2018). Surface Quality Enhancement of Fused Deposition Modeling (FDM) Printed Samples Based on the Selection of Critical Printing Parameters. Materials, 11(8), 1382. https://doi.org/10.3390/ma11081382

[5] Nancharaiah, T., Ranga, R. D., \& Ramachandra, R. V. (2010). An experimental investigation on surface quality and dimensional accuracy of FDM components. International Journal on Emerging Technologies, 1(2), 106-111. Retrieved from http://citeseerx.ist.psu.edu/viewdoc/ download?doi=10.1.1.670.108\&rep=rep1\&type $=$ pdf

[6] Vasudevarao, B., Natarajan, D. P., Henderson, M., \& Razdan, A. (2000). Sensitivity of RP surface finish to 
process parameter variation. Solid Freeform Fabrication Proceedings, 251-258. The University of Texas Austin, TX.

[7] Anitha, R., Arunachalam, S., \& Radhakrishnan, P. (2001). Critical parameters influencing the quality of prototypes in fused deposition modelling. Journal of Materials Processing Technology, 118(1-3), 385-388. https://doi.org/10.1016/S0924-0136(01)00980-3

[8] Ahn, D., Kweon, J.-H., Kwon, S., Song, J., \& Lee, S. (2009). Representation of surface roughness in fused deposition modeling. Journal of Materials Processing Technology, 209(15-16), 5593-5600 https://doi.org/10.1016/j.jmatprotec.2009.05.016

[9] Mahmood, S., Qureshi, A. J., \& Talamona, D. (2018). Taguchi based process optimization for dimension and tolerance control for fused deposition modelling. Additive Manufacturing, 21, 183-190. https://doi.org/10.1016/j.addma.2018.03.009

[10] Knoop, F. \& Schoeppner, V. (2017). Geometrical accuracy of holes and cylinders manufactured with fused deposition modeling. Proceedings of the 28th Annual International Solid Freeform Fabrication Symposium - An Additive Manufacturing Conference, 2753-2776.

[11] Campbell, R. I., Martorelli, M., \& Lee, H. S. (2002). Surface roughness visualisation for rapid prototyping models. Computer-Aided Design, 34(10), 717-725. https://doi.org/10.1016/S0010-4485(01)00201-9

[12] Akande, S. O. (2015). Dimensional Accuracy and Surface Finish Optimization of Fused Deposition Modelling Parts using Desirability Function Analysis. International Journal of Engineering Research \& Technology (IJERT), V4(04), IJERTV4IS040393. https://doi.org/10.17577/IJERTV4IS040393

[13] Altan, M., Eryildiz, M., Gumus, B., \& Kahraman, Y. (2018). Effects of process parameters on the quality of PLA products fabricated by fused deposition modeling (FDM): Surface roughness and tensile strength. Materials Testing, 60(5), 471-477. https://doi.org/10.3139/120.111178

[14] Garg, P. K., Singh, R., \& Ahuja, I. (2017). Multi-objective optimization of dimensional accuracy, surface roughness and hardness of hybrid investment cast components. Rapid Prototyping Journal, 23(5), 845-857. https://doi.org/10.1108/RPJ-10-2015-0149

[15] Armillotta, A., Bianchi, S., Cavallaro, M., \& Minnella, S. (2017). Edge quality in fused deposition modeling: II. experimental verification. Rapid Prototyping Journal, 23(4), 686-695. https://doi.org/10.1108/RPJ-02-2016-0021

[16] Bakar, N. S. A., Alkahari, M. R., \& Boejang, H. (2010). Analysis on fused deposition modelling performance. Journal of Zhejiang University-SCIENCE A, 11(12), 972977. https://doi.org/10.1631/jzus.A1001365

[17] Etesami, F. \& Griffin, T. (2013). Characterizing the Accuracy of FDM Rapid Prototyping Machines for Machine Design Applications. Systems and Design, 12. https://doi.org/10.1115/IMECE2013-64972

[18] Carneiro, O. S., Silva, A. F., \& Gomes, R. (2015). Fused deposition modeling with polypropylene. Materials \& Design, 83, 768-776. https://doi.org/10.1016/j.matdes.2015.06.053

[19] Adel, M., Abdelaal, O., Gad, A., Nasr, A. B., \& Khalil, A. (2018). Polishing of fused deposition modeling products by hot air jet: Evaluation of surface roughness. Journal of Materials Processing Technology, 251, 73-82. https://doi.org/10.1016/j.jmatprotec.2017.07.019

[20] Boschetto, A., Bottini, L., \& Veniali, F. (2016). Finishing of Fused Deposition Modeling parts by CNC machining. Robotics and Computer-Integrated Manufacturing, 41, 92101. https://doi.org/10.1016/j.rcim.2016.03.004

[21] Jin, Y., Wan, Y., Zhang, B., \& Liu, Z. (2017). Modeling of the chemical finishing process for polylactic acid parts in fused deposition modeling and investigation of its tensile properties. Journal of Materials Processing Technology, 240, 233-239. https://doi.org/10.1016/j.jmatprotec.2016.10.003

[22] Gibson, I., Rosen, D. W., \& Stucker, B. (2010). Additive Manufacturing Technologies. https://doi.org/10.1007/978-1-4419-1120-9

[23] Wojtyła, S., Klama, P., \& Baran, T. (2017). Is 3D printing safe? Analysis of the thermal treatment of thermoplastics: ABS, PLA, PET, and nylon. Journal of Occupational and Environmental Hygiene, 14(6), D80-D85. https://doi.org/10.1080/15459624.2017.1285489

[24] Azimi, P., Zhao, D., Pouzet, C., Crain, N. E., \& Stephens, B. (2016). Emissions of Ultrafine Particles and Volatile Organic Compounds from Commercially Available Desktop Three-Dimensional Printers with Multiple Filaments. Environmental Science \& Technology, 50(3), 1260-1268. https://doi.org/10.1021/acs.est.5b04983

[25] Belavendram, N. (1995). Quality by design: Taguchi techniques for industrial experimentation. London: Prentice Hall.

[26] Lee, B. H., Abdullah, J., \& Khan, Z. A. (2005). Optimization of rapid prototyping parameters for production of flexible ABS object. Journal of Materials Processing Technology, 169(1), 54-61. https://doi.org/10.1016/j.jmatprotec.2005.02.259

[27] Sood, A. K., Ohdar, R. K., \& Mahapatra, S. S. (2010). Grey Taguchi Method for Improving Dimensional Accuracy of FDM Process. AIMS International Conference on ValueBased Management, 608-613.

[28] Taguchi, G., Chowdhury, S., \& Wu, Y. (2005). Taguchi's Quality Engineering Handbook. Hoboken, NJ: Wiley. https://doi.org/10.1002/9780470258354

[29] Kacker, R. N., Lagergren, E. S., \& Filliben, J. J. (1991). Taguchi's Orthogonal Arrays Are Classical Designs of Experiments. Journal of Research of the National Institute of Standards and Technology, 96(5), 577-591. https://doi.org/10.6028/jres.096.034

[30] Tošenovský, J. (2012). Plánování experimentů. Retrieved from http://www.person.vsb.cz/archived/FMMI/DOE/ Planovani\%20experimentu.pdf

[31] Moylan, S. P., Slotwinski, J. A., Cooke, A. L., Jurrens, K. K., \& Donmez, M. A. (2012). Proposal for a standardized test artifact for additive manufacturing machines and processes, NIST. https://doi.org/10.6028/NIST.IR.7858

[32] Mendřický, R. (2018). Impact of Applied Anti-Reflective Material on Accuracy of Optical 3D Digitisation. Materials Science Forum, 919, 335-344. https://doi.org/10.4028/www.scientific.net/MSF.919.335

[33] Palousek, D., Omasta, M., Koutny, D., Bednar, J., Koutecky, T., \& Dokoupil, F. (2015). Effect of matte coating on 3D optical measurement accuracy. Optical Materials, 40, 1-9. https://doi.org/10.1016/j.optmat.2014.11.020

\section{Contact information}

Radomir MENDRICKY, Ing., PhD

(Corresponding author)

Technical University of Liberec

Faculty of Mechanical Engineering,

Department of Manufacturing Systems and Automatization,

Studentska 2, 46117 Liberec 1, Czech Republic

radomir.mendricky@tul.cz

Daniel, FRIS, Ing.

Technical University of Liberec,

Faculty of Mechanical Engineering,

Department of Manufacturing Systems and Automatization

Studentska 2, 46117 Liberec 1, Czech Republic

FrisDaniel@seznam.cz 